\title{
Rational addiction and time-consistency: An empirical test ${ }^{\text {光 }}$
}

\author{
Luca Piccoli $^{\mathrm{a}, *}$, Silvia Tiezzi ${ }^{\mathrm{b}}$ \\ ${ }^{\text {a }}$ Department of Sociology and Social Research, University of Trento and IZA, Via Verdi, 26 Trento (I) 38122 \\ ${ }^{\mathrm{b}}$ Department of Economics and Statistics, University of Siena, Piazza San Francesco, 7/8 Siena (I) 53100
}

\section{A R T I C L E I N F O}

\section{JEL classification}

$\mathrm{C} 23$

D03

D12,

\section{Keywords:}

Rational addiction

General versus standard specification

Time-consistency

Naïvete

GMM

\begin{abstract}
A B S T R A C T
This paper addresses one of the main empirical problems associated with rational addiction theory, namely, that its derived demand equation is not empirically distinguishable from those of models with forward-looking behavior but with time-inconsistent preferences. Using an encompassing general specification of the rational addiction model we derive a microfounded test of time-consistency. The test allows us to distinguish between time-consistent versus timeinconsistent naïve agents. The results obtained from a panel of Russian individuals conform to the theoretical predictions of the rational addiction model and the proposed test for time-consistency does not reject the hypothesis that Russian cigarette consumers are time-consistent.
\end{abstract}

\section{Introduction}

Becker and Murphy (1988) explored the dynamic behavior of the consumption of addictive goods, showing how many phenomena previously thought to be irrational can be consistent with utility optimization according to stable preferences. In their model, individuals recognize both the current and future consequences of consuming addictive goods. This model has subsequently become the standard approach to the modeling of the consumption of goods such as cigarettes. A great deal of empirical literature has emerged since then, beginning with Chaloupka (1991), that has tested and generally supported the empirical predictions of the Becker and Murphy model. These past contributions, however, face a number of critical drawbacks.

This paper is concerned with one of these problems, namely, that forward-looking behavior, implied by the model, does not imply time-consistent preferences. Indeed, even when evidence of forward-looking behavior is found, the standard rational addiction demand equation does not allow to separately identify the short-run and long-run discount factors applied to future consumption periods (Gruber and Köszegi, 2001). This is a crucial issue because dynamic inconsistency can deliver radically different implications for government policy. In particular, while time-consistency implies that the optimal tax on addictive goods should depend only on the externalities imposed on society, time-inconsistency suggests a much higher tax depending also on the "internalities" that addictive goods impose on consumers' future selves (Gruber and Köszegi, 2001; O'Donoghue and Rabin, 2006).

This paper offers several contributions to the literature on addiction and time preferences. First, it provides a complete solution to the generalization of the rational addiction model that embeds time-inconsistency through quasi-hyperbolic discounting, a set-up

\footnotetext{
We are grateful to the Editor Mathias Kifmann and two anonymous Reviewers for their helpful and valuable comments and suggestions. Comments from the participants of the $12^{\text {th }}$ European Conference on Health Economics, Maastricht, the Netherlands are gratefully acknowledged. We also thank Pierpaolo Pierani for his input on a much earlier version of the paper, Daniel Kaliski and Davide Dragone for very useful comments on this version of the paper.

* Corresponding author.

E-mail addresses: luca.piccoli@unitn.it (L. Piccoli), silvia.tiezzi@unisi.it (S. Tiezzi).
} 
similar to what proposed by Gruber and Köszegi (2001). We show that while the empirical specification is indistinguishable from the general specification of the rational addiction model (Becker et al., 1990) ${ }^{1}$, the testable implications are richer.

The second contribution consists in providing an estimate, using panel data at the individual level, of the general specification of the rational addiction demand equation that includes current, past and future prices. As far as we know, due to econometric difficulties, this general specification has been estimated before only by Becker et al. (1990), Chaloupka (1991) and Waters and Sloan (1995). Differently from the previous literature, to robustly estimate this specification we propose to use a system-GMM estimator and avoid imposing restrictions on the estimated parameters. This allows us to efficiently obtain meaningful estimates of the structural parameters of interest, such as the long run discount factor, to test for the presence of addiction and to extract additional structural information from the demand equation.

Third, we implement a simple test of time-consistency based on the additional structural information extracted from the general specification of the rational addiction demand equation. The purpose of the proposed test is to disentangle time-consistent versus naïve agents, which is possible because the proposed theoretical framework encompasses rational addiction theory with time-consistency as a special case involving no present bias in time preferences. ${ }^{2}$

Fourth, we show that while the point estimates of the present bias parameter cannot be obtained under the proposed theoretical framework, it is still possible to recover an upper bound, which provides further insights into the degree of time-inconsistency.

The implications of our findings are as follows. First, the rational addiction model and its derived general demand equation (Becker et al., 1990; Becker and Murphy, 1988) can be easily extended to discriminate between time-consistent and naïve time-inconsistent consumers, with the advantage of producing exactly the same empirical specification. Second, the possibility of distinguishing timeconsistent from naïve agents is nested within the same general specification. Stated differently, the information extracted from the general rational addiction demand equation is sufficient for testing both forward-looking behavior and time-consistency. The possibility of testing for time-consistency using field data opens up the opportunity of using the rational addiction demand equation to predict the impact of price measures on the consumption of addictive goods in a more general way. This has relevant policy implications, as time-inconsistent preferences generally imply larger optimal taxes on addictive goods.

The paper proceeds as follows. Section 2 summarizes the literature on time-consistency and addiction. Section 3 reviews the general specification of the rational addiction demand equation. Section 4 introduces quasi-hyperbolic discounting into the above general specification. Section 5 introduces our test of time-consistency. Section 6 describes the data used in the empirical analysis, the estimation methods and instrument choices. Section 7 discusses the results. Section 8 concludes the paper.

\section{Prior research}

The early literature on dynamic consumption behavior modeled impatience in decision making by assuming that agents discount future streams of utility exponentially over time. Exponential discounting is pivotal. Without this assumption, intertemporal marginal rates of substitution will change as time passes, and preferences will be time-inconsistent (Strotz, 1956). Behavioral economics has built on the work of Strotz (1956) to explore the consequences of relaxing the standard assumption of exponential discounting. Ainslie (1992) and Loewenstein and Elster (1992) indicate that some basic features of intertemporal decision-making that are inconsistent with simple models of exponential discounting, namely, that many individuals value consumption in the present more than delayed consumption, may be explained by a particular type of time-inconsistency: hyperbolic discounting. In the formulation of quasi-hyperbolic discounting adopted by Laibson (1997), the degree of present bias is captured by an extra discount parameter $\beta \in(0,1)$, which accounts for instant gratification. Accordingly, the consumption path planned at each time period for the future time periods may never be realized because the intertemporal tradeoff changes over time. The implications of such self-control problems depend on individuals' awareness of their future preferences (O'Donoghue and Rabin, 1999a; 2002). Extreme assumptions about such awareness, e.g., full awareness and full unawareness, identify two types of individuals: naïve and sophisticated (O'Donoghue and Rabin, 1999a; Pollak, 1968; Strotz, 1956). A sophisticated person is fully aware of what her future self preferences will be. A naïve person believes that her future self's preferences will be identical to her current self's preferences, not realizing that as she gets closer to executing decisions, her tastes will have changed. To analyze the equilibrium behavior of individuals with different time preferences, researchers have formally modeled a consumer as a sequence of temporal selves making choices in a dynamic game (Laibson, 1997; O'Donoghue and Rabin, 1999a; 1999b; 2002). Hence, a $T$-period consumption problem translates into a $T$-period game, with $T$ players or selves, indexed by their respective periods of consumption decision. In their analysis of consumption behavior of time-consistent, sophisticated and naïve agents, O'Donoghue and Rabin (1999a, 1999b, 2002) assume individual behavior to be described by perception-perfect strategies, i.e., solution concepts describing the individual's optimal action in all periods given her current preferences and her perception of future behavior. Naïve individuals have present-biased preferences but believe that they are time-consistent. Therefore, the decision process of naïve individuals is identical to that of time-consistent agents, even though

\footnotetext{
${ }^{1}$ We use the expression "general specification" of the demand equation as opposed to the most popular "standard specification", which is usually estimated in the empirical literature on rational addiction. While the general specification includes the current, past and future prices of addictive good as explanatory variables, the standard version only includes current prices. We shall return to this.

${ }^{2}$ In the proposed framework, we are able to discriminate between time-consistent and naïve agents, i.e., time-inconsistent agents that believe to be time-consistent. This is because the equilibrium of both naïve and time-consistent individuals can be solved as an optimization problem and leads to the same empirical demand equation. While time-inconsistent agents could also be sophisticated, i.e., time inconsistent agents that know it and act consequently, the equilibrium of sophisticated agents can only be analyzed through a dynamic game (see O'Donoghue and Rabin, 1999a; 1999b; 2002, for more details), which is out of the scupe of the present paper.
} 
the former have different time preferences, and it amounts to just choosing an optimal future consumption path. This has relevant implications for our study, as both naïve and time-consistent individuals' equilibrium can be solved as an optimization problem.

Since naïve individuals' optimization problem can be formulated to encompass the time-consistent case, its solution and the resulting demand equation offer the opportunity to develop an empirical test for time-consistency. Such distinction is very important from a policy perspective. Because quasi-hyperbolic individuals tend to overconsume the addictive good, the optimal value of a Pigouvian tax on the consumption of addictive goods, for example, increases drastically when present-biased (instead of time-consistent) consumers are considered. This is because the internal costs of impatience add to the external costs caused by consumption of the addictive goods when calculating the optimal level of the Pigouvian $\operatorname{tax}^{3}$

The implications of present-biased preferences and their associated problems of self-control have been studied under a variety of economic choices and environments: Laibson (1997), O'Donoghue and Rabin (1999a), O'Donoghue and Rabin (1999b), O'Donoghue and Rabin (2002), and Angeletos et al. (2001) applied this formulation to consumption and saving behavior; Diamond and Köszegi (2003) explored retirement decisions; Barro (1999) applied it to growth; Gruber and Köszegi (2001), Levy (2010) and, recently, Chaloupka et al. (2019) applied it to smoking behavior; Shapiro (2005) applied it to caloric intake; Fang and Silverman (2009) applied it to the welfare program participation and labor supply of single mothers with dependent children; Della Vigna and Paserman (2005) applied it to job search (see Della Vigna, 2009, for a review); and Acland and Levy (2015) applied it to gym attendance.

Few works have attempted to use a parametric approach to estimate structural dynamic models with hyperbolic time preferences (Fang and Silverman, 2009; Laibson et al., 2007; Paserman, 2008). Focusing on addictive goods, Levy (2010) derives estimates of the degree of present bias using a model of cigarette addiction based on the O'Donoghue and Rabin (2002) generalization of the Becker and Murphy (1988) rational addiction model. Gruber and Köszegi (2001) develop a model incorporating present-biased preferences into the Becker and Murphy framework. In this theory, individuals may change their plan and regret their earlier decisions. The authors propose using their model to obtain the present bias and long-run discounting parameters, and in the unpublished version of the same paper (Gruber and Köszegi, 2000), they propose a test of time-consistency per se for sophisticated agents. Chaloupka et al. (2019) adopt a structural model of smoking cessation that allows for three types of biases: present-biased preferences, naïveté regarding one's degree of present bias, and projection-biased beliefs.

To the best of our knowledge no research has tested the assumption of time-consistency within the structural demand equation derived from the rational addiction model of Becker and Murphy (1988). The standard version of the rational addiction demand equation does not allow for the identification of the short- and long-run discount factor, thus making it impossible to empirically test for time-consistency. However, as we shall explain in the next section, the less popular general formulation of the rational addiction demand equation opens up the possibility of testing for time-consistency.

\section{The general rational addiction demand equation}

Following Boyer $(1978,1983)$ and Becker et al. (1990) (BGM henceforth), considering time as discrete, the individual is assumed to maximize over time the following concave instantaneous utility function:

$$
\sum_{t=1}^{\infty} \delta^{t-1} U_{t}\left(C_{t}, A_{t}, Y_{t}, e_{t}\right)
$$

where $C_{t}$ is the quantity of a single addictive good consumed in period $t, A_{t}$ is the stock of past consumption in period $t, Y_{t}$ is the consumption of a composite commodity in period $t$ and $e_{t}$ reflects the impact of unmeasured lifecycle variables on utility. $\delta=$ $\frac{1}{(1+r)}$ is the long-run discount factor and $r$ is the individual rate of time preference. Preferences are stationary in the sense that the instantaneous utility function, $U_{t}(\cdot)$, in equation (1) does not change over time, meaning that a person's instantaneous utility function depends on her current consumption level but not on the specific period $t$. This utility function has the following properties: $\frac{\partial U_{t}}{\partial C_{t}}>0$, $\frac{\partial U_{t}}{\partial Y_{t}}>0$, and $\frac{\partial U_{t}}{\partial A_{t}}<0$. Utility maximization is subject to the lifetime budget constraint $W_{0}=\sum_{t=1}^{\infty} \delta^{t-1}\left(Y_{t}+P_{t} C_{t}\right)$, where $W_{0}$ is the present value of wealth, and $P_{t}$ is the relative price of the addictive good at time $t$. The evolution of the addictive stock $A_{t}$ is described by a simple investment function, $A_{t}=(1-\gamma) A_{t-1}+C_{t-1}$, where $\gamma$ measures the depreciation rate of the stock over time and represents the exogenous rate of disappearance of the physical and mental effects of past consumption (Becker and Murphy, 1988). When the stock depreciates completely in one time period, the depreciation rate is $\gamma=1$ and $A_{t}=C_{t-1}$. Assuming that this restriction holds, considering a quadratic instantaneous utility function in the three arguments ${ }^{4}$ subject to the intertemporal budget constraint, and solving the first-order conditions for $C_{t}$ and $A_{t}$, BGM obtains the following second-order difference demand equation:

$$
C_{t}=\theta_{0}+\theta C_{t-1}+\theta \delta C_{t+1}+\theta_{1} P_{t}
$$

\footnotetext{
${ }^{3}$ Since the equilibrium of sophisticated individuals cannot be solved as an optimization problem, our empirical analysis and our test of timeconsistency do not apply to sophisticated agents. O'Donoghue and Rabin (1999a) stress that even though sophistication is closer to standard economic assumptions than naïveté, it may have departures from conventional predictions that are even more extreme than those implied by naïveté. Focusing on naïve individual only produces results that arise from present-biased preferences only, rather than from present-biased preferences in conjunction with sophistication. In addition, naïveté may be more empirically relevant than sophistication, as suggested by Ariely and Wertenbroch (2002) and Della Vigna and Malmendier (2006).

${ }^{4}$ This is a standard assumption in the rational addiction literature. The quadratic specification delivers linear first-order conditions that allow for empirical estimation.
} 
Equation (2) expresses current consumption as a function of past and future consumption and the current price $P_{t}$. This is the restricted or standard formulation of the rational addiction demand equation usually estimated in the empirical literature. ${ }^{5}$

Assuming that the stock of addiction depreciates completely in one time period, as implied by $\gamma=1$, is, however, a rather strong assumption. A more realistic one would be $\gamma<1$ which implies that the physical and mental effects of past consumption disappear at a slower pace, involving more than one time period. In the more general case, i.e., with $\gamma<1$, we have past and future prices entering equation (2) (Becker et al., 1990; Chaloupka, 1990):

$$
C_{t}=\theta_{0}+\theta C_{t-1}+\theta \delta C_{t+1}-\theta_{1}\left[1+(1-\gamma)^{2} \delta\right] P_{t}+\theta_{1}(1-\gamma) P_{t-1}+\theta_{1}(1-\gamma) \delta P_{t+1}
$$

Equation (3) is a generalization of equation (2), and we will refer to it as the demand equation of the general specification of the rational addiction model.

A serious problem in estimating this general specification is the likely high collinearity between prices, possibly resulting in a low statistical significance of the relevant effects. This was serious especially in the early nineties, when empirical tests of the rational addiction model spread rapidly, and the use of aggregated rather than individual data was the most common practice. To overcome this problem, Becker et al. (1990), Chaloupka (1990) and Waters and Sloan (1995) impose some restrictions implied by theory. In particular, since the ratio of future-to-past price effects is equal to the ratio of future-to-past consumption effects, i.e.,

$$
\frac{\frac{\partial C_{t}}{\partial P_{t+1}}}{\frac{\partial C_{t}}{\partial P_{t-1}}}=\frac{\frac{\partial C_{t}}{\partial C_{t+1}}}{\frac{\partial C_{t}}{\partial C_{t-1}}}=\delta
$$

the coefficients of $P_{t+1}$ and $C_{t+1}$ are equal to the respective past effects multiplied by the discount factor, thus reducing the number of parameters to be estimated. This implies imposing an exogenous value for the rate of time preference. Becker et al. (1990), Chaloupka (1990) and Waters and Sloan (1995) find that this restriction is valid and improves the statistical significance of the price and consumption coefficients. The difficult identification of price effects in the general specification explains why the vast empirical literature on rational addiction has focused on estimating the restricted equation (2) instead of the general specification (3).

However, such historical focus on the restricted demand equation has cast in the shade the fundamental distinction between the restricted version and the general one, and the great advantage of the latter is that it provides deeper insights into intertemporal preferences.

Building on these considerations, we show that by introducing quasi-hyperbolic discounting into the general version of the rational addiction model, it is possible to develop an easy test, allowing us to distinguish time-consistent from naïve consumers.

\section{Quasi-Hyperbolic discounting}

In what follows, we embed quasi-hyperbolic discounting of future utilities á la Laibson (1997) in equation (1). We solve the maximization problem step by step by reproducing passages from Chaloupka (1990) in Appendix A.

O'Donoghue and Rabin (1999b, 2002) show that, under the stationarity of preferences, for both time-consistent and naïve individuals, the infinite-horizon perception-perfect strategy is unique and corresponds to the unique finite-horizon perception-perfect strategy as the horizon, $T$, becomes long. Therefore, in what follows, we will keep assuming an infinite time horizon $T=\infty$, a common assumption in rational addiction models. Individuals are assumed to maximize the sum of lifetime discounted utility

$$
\text { Max } U_{t}+\beta \sum_{i=1}^{\infty} \delta^{i} U_{t+i}=U_{t}+\beta \delta U_{t+1}+\beta \delta^{2} U_{t+2}+\ldots
$$

where $\delta=\frac{1}{(1+r)}$ is the long-run discount factor, $r$ is the discount rate (that coincides with the interest rate in the budget constraints), and the extra discount parameter $\beta \in(0,1]$ is intended to capture the essence of hyperbolic discounting, namely, that the discount factor between consecutive future periods $(\delta)$ is larger than that between the current period and the next period $(\beta \delta)$. If $\beta \neq 1$, time preferences in equation (4) are dynamically inconsistent, in the sense that preferences at date $t$ are inconsistent with preferences at date $t+1 .^{6}$ As shown by O'Donoghue and Rabin (2002), the equilibrium of both naïve and time-consistent individuals solve the same optimization problem, therefore, the demand equation that solves (4) applies to both time-consistent and naïve consumers. As in the general specification of the rational addiction model, the interaction between past and future consumption is modeled by the investment function $A_{t}=(1-\gamma) A_{t-1}+C_{t-1}$, with $\gamma<1$. The consumer solves the maximization problem such that $C_{0}=C^{0}$ and $\left(Y_{t}+P_{t} C_{t}\right)+\sum_{i=1}^{\infty} \delta^{i}\left(Y_{t+i}+P_{t+i} C_{t+i}\right)=W_{0}$, where $C^{0}$ measures the previous level of addictive consumption.

\footnotetext{
5 See, for example, Baltagi and Griffin (2001, 2002) Baltagi and Geishecker (2006), Grossman and Chaloupka (1998), Grossman et al. (1998), Gruber and Köszegi (2001), Jones and Labeaga (2003), Labeaga (1993, 1999), Liu et al. (1999), Olekalns and Bardsley (1996), Saffer and Chaloupka (1999), Ziliak (1997).

6 Halevy (2015) shows that a decision-maker is time-consistent if and only if her preferences are both stationary and time-invariant. Since the preferences in our model are assumed to be stationary, our test of time-consistency reduces to a test of time-invariance. Time-invariance requires the preferences for future consumption streams to be the same in each evaluation period. See Halevy (2015) page 341 for a formal definition of time invariance.
} 
Taking a quadratic utility function in the three arguments and solving the consumer problem produces the following Euler equation: ${ }^{7}$

$$
C_{t}=\theta_{0}+\theta_{L} C_{t-1}+\theta_{F} \delta C_{t+1}-\theta_{1}\left[1+(1-\gamma)^{2} \delta\right] P_{t}+\theta_{1}(1-\gamma) P_{t-1}+\theta_{1} \delta(1-\gamma) P_{t+1}
$$

where:

$$
\begin{aligned}
\Omega & =\alpha_{C A}(1+\beta) \delta(1-\gamma)-\alpha_{A A} \beta \delta-\alpha_{C C}\left[1+\delta(1-\gamma)^{2}\right]>0 \\
\theta_{0} & =\frac{\gamma}{\Omega}\left[\kappa+\alpha_{C}(\delta(1-\gamma)-1)-\alpha_{A} \beta \delta\right] \\
\theta_{L} & =\frac{1}{\Omega}\left[\alpha_{C A}-\alpha_{C C}(1-\gamma)\right]>0 \\
\theta_{F} & =\frac{1}{\Omega}\left[\beta \alpha_{C A}-\alpha_{C C}(1-\gamma)\right]>0 \\
\theta_{1} & =\frac{\lambda}{\Omega}>0
\end{aligned}
$$

Equation (5) is very similar to equation (3), except that the coefficient $\theta$ that multiplies $C_{t+1}$ and $C_{t-1}$ here is not exactly the same. The difference between $\theta_{L}$ and $\theta_{F}$ is that the $\alpha_{C A}$ parameter in equation (7) is multiplied by $\beta$.

\section{Testing time-consistency}

The rational addiction model with quasi-hyperbolic discounting encompasses the original formulation of the rational addiction model. In particular setting $\beta=1$ the model reduces to the standard BGM rational addition model, which implies time-consistency. Equation (5) can thus be used to test whether consumers are time-consistent or not by testing the equality $\theta_{L}=\theta_{F}$.

Recalling that the empirical reduced form of the demand equation (5) is identical to the general formulation of the rational addiction demand equation, i.e. ${ }^{8}$

$$
C_{i t}=\phi_{0}+\phi_{L} C_{i t-1}+\phi_{F} C_{i t+1}+\varphi_{T} P_{i t}+\varphi_{L} P_{i t-1}+\varphi_{F} P_{i t+1}
$$

if no parameters restrictions are imposed, it is possible to identify all needed coefficients to perform the standard battery of tests for the rational addiction model and, in addition, to test for time-consistency.

Proposition 1. By estimating equation (8), it is possible to test for time-consistency applying a standard nonlinear hypothesis test, i.e., $\hat{\phi}_{L} \hat{\varphi}_{F}=\hat{\phi}_{F} \hat{\varphi}_{L}$.

Proof. The estimation of equation (8) is sufficient to recover all parameters required to test whether $\beta=1$. Indeed:

$$
\begin{aligned}
\delta & =\frac{\hat{\varphi}_{F}}{\hat{\varphi}_{L}} \\
\theta^{L} & =\hat{\phi}_{L} \\
\theta^{F} & =\frac{\hat{\phi}_{F}}{\delta}=\frac{\hat{\phi}_{F} \hat{\varphi}_{L}}{\hat{\varphi}_{F}} .
\end{aligned}
$$

From equations (6) and (7) it is possible to note that $\beta=1$ if and only if $\theta_{L}=\theta_{F}$, i.e., $\hat{\phi}_{L} \hat{\varphi}_{F}=\hat{\phi}_{F} \hat{\varphi}_{L}$

If the test rejects the null hypothesis, then $\beta \neq 1$ and the data do not support time-consistent preferences, as implied by the BGM rational addiction model, in favor of quasi-hyperbolic discounting for naïve agents.

Given the parametric specification of equation (5) and the corresponding reduced-form equation (8), it is not possible to directly identify the value of the present bias parameter $\beta$. Nevertheless, it is possible to find an upper limit for $\beta$ compatible with the estimated coefficients.

Corollary 1. The upper limit for the present-bias parameter $\beta$ compatible with the estimated coefficients is $\beta_{\max }=\frac{\hat{\phi}_{F} \hat{\varphi}_{L}}{\hat{\phi}_{L} \hat{\varphi}_{F}}$.

Proof. From equations (6) and (7), the ratio of consumption coefficients can be written as

$$
\frac{\theta_{F}}{\theta_{L}}=\frac{\beta \alpha_{C A}-\alpha_{C C}(1-\gamma)}{\alpha_{C A}-\alpha_{C C}(1-\gamma)},
$$

from which an expression for $\beta$ can be obtained, i.e.,

$$
\beta=\frac{\theta_{F}}{\theta_{L}}+\left(1-\frac{\theta_{F}}{\theta_{L}}\right)(1-\gamma) \frac{\alpha_{C C}}{\alpha_{C A}}
$$

\footnotetext{
${ }^{7}$ For a detailed derivation of the Euler equation, see Appendix A.

${ }^{8}$ For simplicity of exposition, we omit from the equation further covariates and the error terms, which will be introduced later in the empirical section.
} 
Table 1

Evolution of consumption and price of cigarettes.

\begin{tabular}{llllll}
\hline & \multicolumn{2}{c}{ Nr. of cigarettes } & & \multicolumn{2}{c}{ Price of cigarettes } \\
\cline { 2 - 3 } \cline { 5 - 6 } Year & Mean & Std. Dev. & & Mean & Std. Dev. \\
\hline 2006 & 15.4 & 8.0 & & 10.8 & 3.5 \\
2007 & 15.7 & 8.2 & & 12.5 & 7.2 \\
2008 & 15.5 & 8.2 & & 12.3 & 5.4 \\
2009 & 15.5 & 8.2 & & 13.4 & 6.5 \\
2010 & 15.7 & 8.6 & & 16.9 & 7.8 \\
2011 & 15.8 & 8.5 & & 18.1 & 6.0 \\
2012 & 16.1 & 8.5 & & 19.4 & 5.3 \\
2013 & 15.8 & 8.4 & & 23.3 & 7.5 \\
2014 & 15.1 & 8.1 & & 23.6 & 6.1 \\
2015 & 15.2 & 8.1 & & 26.4 & 6.8 \\
2016 & 14.9 & 7.7 & & 28.0 & 6.2 \\
2017 & 14.7 & 7.5 & 30.6 & 6.8 \\
2018 & 14.3 & 7.3 & 32.2 & 12.4 \\
\hline
\end{tabular}

Thus, $\beta$ is a linear function of the unknown ratio $\alpha_{C C} / \alpha_{C A}$. If, as suggested by theory, $\alpha_{C A}$ is positive, $\alpha_{C C}$ is negative, and $\beta \leq 1$, then by equations (6) and (7) the function is increasing in the $\alpha_{C C} / \alpha_{C A}$ ratio, and a natural upper bound for equation (9) is reached when $\alpha_{C C}=0$, i.e., $\beta^{\max }=\frac{\theta_{F}}{\theta_{L}}=\frac{\hat{\phi}_{F} \hat{\varphi}_{L}}{\hat{\phi}_{L} \hat{\varphi}_{F}}$.

We report the outcome of these tests in the results section.

\section{Data and empirical strategy}

\subsection{Data preparation}

The empirical analysis of cigarette addiction in Russia is based on 13 waves (from 2006 to 2018) of the Russia Longitudinal Monitoring Survey (RLMS-HSE). The survey is conducted by the Higher School of Economics and ZAO Demoscop, together with the Carolina Population Center, and follows individuals and their families from childhood to adulthood. ${ }^{9}$ Households participating in the survey were selected through a multistage probability sampling procedure to guarantee cross-sectional national representativeness. Within each of the 38 primary sample units (PSUs), the population was stratified into urban and rural substrata to guarantee the representativeness of the sample in both areas. The survey covers approximately $5000 \mathrm{hh}, 12,000$ adults and 2000 children (aged up to 15 years) per wave.

For each individual aged 13 years and above, the survey asks whether she/he smokes and, if so, the number of cigarettes smoked per day. This is the main consumption measure used in our study. The household questionnaire also asks about family tobacco expenditure and quantity, but that is at the household level and is not suitable for individual consumption analysis. The price variable is computed from the community questionnaire, where interviewers go to local stores in the community and check minimum and maximum prices of a large sample of commodities, including domestic- and foreign-branded cigarettes. Because several missing values are recorded at the community level (if, for instance, no store had a particular item or if the store was closed), the price was averaged across communities within the same primary sample units to reduce the impact of measurement errors. Because the prices are at the current level, and the survey does not provide consumer price indices to deflate prices, we compute a consumer price index at the PSU level following the Törnqvist procedure (Törnqvist, 1936). The reference price is that of the Moscow PSU in 1998, and the index is computed on a wide set of food commodities, excluding tobacco and alcohol items. Cigarette prices-together with the other monetary variables described below-are then deflated using this consumer price index.

The original sample for 2006 to 2018 is composed of 43,247 individuals and 237,579 observations, of which 9179 individuals and 40,335 observations are in the child questionnaire, assigned to children up to 12, which does not record information on smoking. Retaining only smokers reduces the sample to 14,423 individuals and 60,754 observations, while selecting individuals in the age range 22-74 and keeping only singles or families with at most 2 children further restricts the sample to 11,415 individuals and 45,238 observations. Given that the estimation of the structural model requires the observation of at least three consecutive time periods for each individual, the actual estimation sample is composed of 5924 individuals and 24,006 observations. When adding covariates, some of which are measured with a small number of missing values, the estimation sample is composed of 5789 individuals and 22,346 observations.

The evolution of consumption and the price of cigarettes in the estimation sample is presented in Table 1. Among smokers, the number of cigarettes per day is fairly stable, with a slight decrease only after 2012. The real price of a pack of cigarettes instead shows a substantial increase over time, with a faster growth since 2010. This is in part due to stronger antitobacco policies that have resulted in increasing excise taxes starting in 2010, when nominal excises were approximately 6.6 rubles, to 2018 , when excises were approximately 85.9 rubles.

\footnotetext{
${ }^{9}$ More information can be found in the RLMS-HSE site: http://www.cpc.unc.edu/projects/rlms-hse.
} 
Table 2

Descriptive statistics of the control variables.

\begin{tabular}{lllll}
\hline Variable & Mean & Std. Dev. & Min & Max \\
\hline Female & 0.29 & 0.45 & 0 & 1 \\
Age & 41.9 & 12.8 & 22 & 74 \\
BMI & 25.6 & 4.7 & 12.2 & 61.1 \\
Work hours in a typical working day & 7.2 & 5.8 & 0 & 24 \\
Monthly wage & 14,230 & 16,870 & 0 & 400,000 \\
Years of education & 15.9 & 3.9 & 0 & 23 \\
\hline
\end{tabular}

This information would be sufficient to estimate the model presented in equation (8), but the introduction of control variables can improve the precision of estimates. ${ }^{10}$ The control variables used in estimation include age, gender, labor market status (work hours on a typical working day and monthly wage), years of education and body mass index.

The descriptive statistics of the control variables for the estimation sample are reported in Table 2 . The estimation sample is clearly male dominated (more than 70\%), has an average age of approximately 42 and has an average body mass index of 25.6 , indicating that this sample of smokers tends to be overweight. The typical working day is only slightly above 7 hours, an average that includes non-working individuals and a small share of people who work 24 hours per day (in the days they work). The average monthly wage is about 14 thousands Rubles and the average education is almost 16 years.

\subsection{Estimating the general rational addiction model}

Our empirical demand equation is a variant of equation (8):

$$
C_{i t}=\phi_{0}+\phi_{L} C_{i t-1}+\phi_{F} C_{i t+1}+\varphi_{T} P_{i t}+\varphi_{L} P_{i t-1}+\varphi_{F} P_{i t+1}+\eta_{x} X_{i t}+v_{i}+d_{t}+u_{i t}
$$

where $C_{i t}$ is the number of cigarettes smoked by individual $i$ in period $t, P_{i t}$ is the real price of cigarettes, $X_{i t}$ is a vector of exogenous economic and sociodemographic variables that affect cigarette consumption, $v_{i}$ are individual fixed effects capturing time-invariant preferences that are correlated with lead and lagged consumption and probably with other determinants of consumption, $d_{t}$ are time fixed effects, and $u_{i t}=\xi_{1} e_{t}+\xi_{2} e_{t+1}$ is the idiosyncratic error term. The OLS estimates of the dynamic panel data equation (10) can suffer from an omitted variable bias due to unaccounted demand shifters that may also be serially correlated (Becker et al., 1994).

To correct for the endogeneity bias, we follow Arellano and Bond (1991) in using a GMM procedure to obtain the vector of parameters. The GMM estimators exploit a set of moment conditions between instrumental variables and time-varying disturbances. The basic idea is to take first-differences to deal with the unobserved fixed effects and then use the suitably lagged levels of the endogenous and predetermined variables as instruments for the first differenced series, under the assumption that the error term in levels is spherical and taking into account the serial correlation induced by the first-difference transformation. This idea extends to the case of the lags and leads of the dependent variable and to the case where serial correlation already exists in the error term of the original model, as in equation (10).

After first differencing equation (10) becomes

$$
\Delta C_{i t}=\phi_{L} \Delta C_{i t-1}+\phi_{F} \Delta C_{i t+1}+\varphi_{T} \Delta P_{i t}+\varphi_{L} \Delta P_{i t-1}+\varphi_{F} \Delta P_{i t+1}+\eta_{x} \Delta X_{i t}+\eta_{d} \Delta d_{t}+\Delta u_{i t}
$$

the strategy is to find a set of instruments $Z_{i t}$ that are uncorrelated with the first-differenced error term $\Delta u_{i t}$ and correlated with the regressors. By definition,

$$
\Delta u_{i t}=\xi_{1} \Delta e_{t}+\xi_{2} \Delta e_{t+1}
$$

for $i=1, \ldots, N$ and $t=3, \ldots, T-1$. Given the error term $\Delta u_{i t}$ in (12), the following moment conditions are available: $E\left(C_{i t-s} \Delta u_{i t}\right)=$ 0 for $t=4, \ldots, T-1$ and $s \geq 3$. This allows for the use of lagged levels of observed consumption series dated $t-3$ and earlier as instruments for the first-differenced equation (11). The moment restrictions can be written in matrix form as $E\left(Z_{i}^{\prime} \Delta u_{i}\right)=0$ for $t=$ $4, \ldots, T-1$, where $\Delta u_{i}$ is the $(T-4)$ vector $\left(\Delta u_{i 4}, \Delta u_{i 5}, \ldots, \Delta u_{i T-1}\right)^{\prime} . \Delta u_{i}=u_{i t}-u_{i t-1}$ and $Z_{i}$ is a $(T-4) \times g$ block diagonal matrix, whose $i^{\text {th }}$ block is given as

$$
Z_{i}=\left(\begin{array}{cccccccc}
C_{i t} & 0 & 0 & \ldots & 0 & \ldots & 0 & \Delta W_{i 4}^{\prime} \\
0 & C_{i 1} & C_{i 2} & \ldots & 0 & \ldots & 0 & \Delta W_{i 5}^{\prime} \\
\vdots & \vdots & \vdots & \ldots & \vdots & \vdots & \vdots & \vdots \\
0 & 0 & 0 & \ldots & C_{i 1} & \ldots & C_{i T-4} & \Delta W_{i T-1}^{\prime}
\end{array}\right),
$$

\footnotetext{
${ }^{10}$ In addition, as for most panel data surveys, the RLMS also suffers from a certain level of attrition. According to Gerry and Papadopoulos (2015), who analyzed the years 2001-2010, the average yearly attrition rate is below 10\%, but attrition is significantly correlated with some individual characteristics that make a missing completely at random assumption implausible. Given that several studies show relatively small attrition biases, in the current work, instead of applying more rigorous and complex correction techniques, we opted to include in the list of control variables those characteristics that have been proven to be relevant for attrition in Gerry and Papadopoulos (2015). Our working hypothesis is that if the parameters of interest do not vary substantially with the inclusion of these controls, then attrition should generate small biases.
} 
where the block diagonal structure at each time period exploits all of the instruments available, concatenated to one-column first-differenced exogenous regressors $\Delta W_{i t}^{\prime}=\left(\Delta P_{i t}, \Delta P_{i t-1}, \Delta P_{i t+1}, \Delta X_{i t}\right)$, which act as instruments for themselves (Arellano and Bond, 1991).

Ever since the work of BGM on US cigarette consumption, past and future prices have been considered natural instruments for lagged and lead consumption. We maintain this pivotal option here.

The first-differenced GMM estimator is poorly behaved in terms of finite sample properties (bias and imprecision) when instruments are weak. This can occur here, given that the lagged levels of consumption are usually only weakly correlated with the subsequent first differences. More plausible results and better finite sample properties can be obtained using a system-GMM estimator (Arellano and Bover, 1995; Blundell and Bond, 1998). This augmented version exploits additional moment conditions, which are valid under the mean stationarity of the initial condition. This assumption yields $(T-4)$ further linear moment conditions that allow for the use of equations in levels with suitably lagged first differences of the series as instruments:

$$
E\left(\Delta C_{i t-2} u_{i t}\right)=0 \text { for } t=4, \ldots, T-1
$$

The complete system of moment conditions available can be expressed as $E\left(Z_{i}^{+^{\prime}} u_{i}^{+}\right)=0$, where $u_{i}^{+}=\left(\Delta u_{i 4}, \ldots, \Delta u_{i T-1}, u_{i 4}, \ldots, u_{i T-1}\right)^{\prime}$. The instrument matrix for this system is

$$
Z_{i}^{+}=\left(\begin{array}{ccccc}
Z_{i} & 0 & 0 & \ldots & 0 \\
0 & \Delta C_{i 2} & 0 & \ldots & 0 \\
0 & 0 & \Delta C_{i 3} & \ldots & 0 \\
\vdots & \vdots & \vdots & \ldots & \vdots \\
0 & 0 & 0 & \ldots & \Delta C_{i T-3}
\end{array}\right) .
$$

Whether we actually need all these moment conditions is debatable, since in finite samples, there is a bias/efficiency tradeoff (Biørn and Klette, 1998). A large instrument collection, such as that generated by the system GMM, overfits the endogenous explanatory variables and weakens the power of the overidentification tests (Roodman, 2009b). Ziliak (1997) showed that GMM may perform better with suboptimal instruments and argued against using all available moments.

We use only a subset of these moments in our preferred specification. After experimentation with the instruments, we report in the next section estimates using the following parsimonious matrix of instruments $Z_{i}$ in our preferred specifications (columns 5 and 6 in Table 3), which represent compromises among theory, previous applied work and the characteristics of the data:

$$
Z_{i}=\left(\begin{array}{ccccc}
C_{i 1}, P_{i 3}, P_{i 5}, X_{i 4} & 0 & \ldots & 0 & \Delta W_{i 4}^{\prime} \\
0 & C_{i 2}, P_{i 4}, P_{i 6}, X_{i 5} & \ldots & 0 & \Delta W_{i 5}^{\prime} \\
\vdots & \vdots & \ldots & \vdots & \vdots \\
0 & 0 & \ldots & C_{i T-4}, P_{i T-2}, P_{i T}, X_{i T-1} & \Delta W_{i T-1}^{\prime}
\end{array}\right)
$$

where the least informative lagged levels of consumption have been dropped.

The performance of system GMM in finite samples has been under scrutiny in the recent literature (Bun and Kleibergen, 2013; Bun and Sarafidis, 2013). One issue that has attracted attention is the credibility of the assumption described as "constant correlated effects" by Bun and Sarafidis (2013) and employed for deriving the additional moment conditions made available by system GMM. ${ }^{11}$ This assumption requires the correlation between the variables and the unobserved time-invariant heterogeneity to be constant over time, $E\left(y_{i t} v_{i}\right)=c_{y}$ and $E\left(x_{i t} v_{i}\right)=c_{x}$, so that first-differenced variables are uncorrelated with the individual effects, $E\left(\Delta y_{i t} v_{i}\right)=0$ and $E\left(\Delta x_{i t} v_{i}\right)=0$ (Bun and Sarafidis, 2013, page 13). For this assumption to be valid, changes in the instrumenting variables must be uncorrelated with the fixed effects. In our context, this means that throughout our study period, deviations from steady-state cigarette consumption levels are not systematically related to unobserved fixed effects such as family background, genetics or (slowly varying) social norms about smoking. Whether these conditions are satisfied is an empirical question. To test for the validity of this assumption, we use difference overidentifying restrictions tests. In particular, we use the difference between the overidentifying restrictions in the system and difference GMM statistics.

\section{Results and discussion}

The empirical specification (10) uses the number of cigarettes smoked per day as the dependent variable, restricting our sample to smokers only. All models are estimated for individuals between 22 and 74 years of age, for a household size not larger than 4 individuals and for thirteen waves: 2006 to 2018. The actual number of observations used in estimation varies depending on the specification, the estimator, and the choice of instruments. In our preferred specification, we use 17,387 observations and 4675 individuals.

The right-hand-side variables are the lead and lag consumption, current, lead and lag real price of cigarettes at the PSU level from the community questionnaire, and a number of sociodemographic characteristics described in Section 6. In all specifications, we use time dummies to make the assumption of no correlation across individuals in the idiosyncratic disturbances more likely to hold (Roodman, 2009a).

11 This assumption is often labeled the "mean stationarity" assumption. However, Bun and Sarafidis (2013) notice that this is a somewhat imprecise definition because the additional moment conditions in system GMM do not require mean stationarity. 
Table 3

Estimates of the General Rational Addiction Models

\begin{tabular}{|c|c|c|c|c|c|c|}
\hline Parameter & $\begin{array}{l}\text { OLS } \\
(1)\end{array}$ & $\begin{array}{l}\text { Fixed Effects } \\
\text { (2) }\end{array}$ & $\begin{array}{l}\text { DIFF-GMM } \\
\text { (3) }\end{array}$ & $\begin{array}{l}\text { SYS-GMM } \\
\text { (4) }\end{array}$ & $\begin{array}{l}\text { DIFF-GMM } \\
\text { (5) }\end{array}$ & $\begin{array}{l}\text { SYS-GMM } \\
\text { (6) }\end{array}$ \\
\hline$C_{t-1}$ & $\begin{array}{l}0.395^{* * *} \\
(0.009)\end{array}$ & $\begin{array}{l}-0.017 \\
(0.012)\end{array}$ & $\begin{array}{l}0.355^{* * *} \\
(0.034)\end{array}$ & $\begin{array}{l}0.379^{* * *} \\
(0.032)\end{array}$ & $\begin{array}{l}0.384^{* * * *} \\
(0.060)\end{array}$ & $\begin{array}{l}0.407^{* * *} \\
(0.043)\end{array}$ \\
\hline$C_{t+1}$ & $\begin{array}{l}0.413^{* * *} \\
(0.009)\end{array}$ & $\begin{array}{l}-0.015 \\
(0.012)\end{array}$ & $\begin{array}{l}0.273^{* * *} \\
(0.040)\end{array}$ & $\begin{array}{l}0.327^{* * * *} \\
(0.037)\end{array}$ & $\begin{array}{l}0.286^{* * * *} \\
(0.058)\end{array}$ & $\begin{array}{l}0.399^{* * *} \\
(0.046)\end{array}$ \\
\hline$P_{t}$ & $\begin{array}{l}-0.014^{* *} \\
(0.006)\end{array}$ & $\begin{array}{l}0.006 \\
(0.008)\end{array}$ & $\begin{array}{l}-0.010 \\
(0.010)\end{array}$ & $\begin{array}{l}-0.009 \\
(0.009)\end{array}$ & $\begin{array}{l}-0.017 \\
(0.057)\end{array}$ & $\begin{array}{l}-0.081^{* * *} \\
(0.020)\end{array}$ \\
\hline$P_{t-1}$ & $\begin{array}{l}0.010^{*} \\
(0.006)\end{array}$ & $\begin{array}{l}0.020^{* * * *} \\
(0.008)\end{array}$ & $\begin{array}{l}0.014^{*} \\
(0.008)\end{array}$ & $\begin{array}{l}0.013 \\
(0.008)\end{array}$ & $\begin{array}{l}0.014 \\
(0.047)\end{array}$ & $\begin{array}{l}0.0309^{* *} \\
(0.0156)\end{array}$ \\
\hline$P_{t+1}$ & $\begin{array}{l}0.000 \\
(0.005)\end{array}$ & $\begin{array}{l}-0.002 \\
(0.006)\end{array}$ & $\begin{array}{l}-0.005 \\
(0.007)\end{array}$ & $\begin{array}{l}-0.008 \\
(0.006)\end{array}$ & $\begin{array}{l}0.003 \\
(0.029)\end{array}$ & $\begin{array}{l}0.0306^{* *} \\
(0.0138)\end{array}$ \\
\hline Female & & & & & & $\begin{array}{l}-0.987^{* * *} \\
(0.258)\end{array}$ \\
\hline Age & & & & & $\begin{array}{l}-0.109 \\
(0.371)\end{array}$ & $\begin{array}{l}0.010^{* * *} \\
(0.004)\end{array}$ \\
\hline BMI & & & & & $\begin{array}{l}0.039 \\
(0.030)\end{array}$ & $\begin{array}{l}0.024^{* *} \\
(0.010)\end{array}$ \\
\hline Hours of work & & & & & $\begin{array}{l}0.055^{* * *} \\
(0.014)\end{array}$ & $\begin{array}{l}0.031^{* * *} \\
(0.008)\end{array}$ \\
\hline Years of education & & & & & $\begin{array}{l}-0.011 \\
(0.033)\end{array}$ & $\begin{array}{l}-0.034^{* * *} \\
(0.012)\end{array}$ \\
\hline Monthly wage & & & & & $\begin{array}{l}0.000 \\
(0.000)\end{array}$ & $\begin{array}{l}0.000^{* *} \\
(0.000)\end{array}$ \\
\hline Time dummies & yes & yes & yes & yes & yes & yes \\
\hline Constant & $\begin{array}{l}3.154^{* * * *} \\
(0.159)\end{array}$ & $\begin{array}{l}11.507^{* * *} \\
(0.285)\end{array}$ & & & & \\
\hline Hansen p-val full & & & 0.210 & 0.111 & 0.156 & 0.392 \\
\hline Hansen p-val transf. model & & & & 0.252 & & 0.349 \\
\hline Diff-in-Hansen p-val & & & & 0.022 & & 0.520 \\
\hline p-val AR(2) Arellano-Bond in FD & & & 0.000 & 0.000 & 0.000 & 0.000 \\
\hline p-val AR(3) Arellano-Bond in FD & & & 0.910 & 0.669 & 0.589 & 0.950 \\
\hline \# Obs & 24,006 & 24,006 & 18,467 & 24,006 & 13,007 & 17,387 \\
\hline $\begin{array}{l}\text { Instruments count } \\
\text { time-consistency test } \chi^{2}(1) \\
\text { p-value }\end{array}$ & & & 676 & 741 & 200 & $\begin{array}{l}292 \\
0.00 \\
0.991\end{array}$ \\
\hline
\end{tabular}

Notes: Robust SE in parentheses. Windmeijer correction used in models (3)-(6).

* $\mathrm{p}<0.10$, ** $\mathrm{p}<0.05$, *** $\mathrm{p}<0.01$.

To avoid instrument proliferation we limit the lags used in GMM-style instruments. Our chosen estimator is the system GMM (Blundell and Bond, 1998). This unifying GMM framework incorporates orthogonality conditions of both types of equations, transformed and in levels, and performs significantly better in terms of efficiency compared to other IV estimators of dynamic panel data models. We estimate both one-step and two-step system-GMM estimators, but we only report two-step estimates with a robust covariance matrix using the Windmeijer (2005) correction.

In terms of the empirical studies and finite sample properties of the GMM estimator, the choice of transformation used to remove individual effects is important. First differencing (FD) is one option, but Arellano and Bover (1995) propose an alternative transformation for models with predetermined instruments: forward orthogonal deviations (FOD). This transformation involves subtracting the mean of all future observations for each individual. The key difference between FD and FOD is that the latter does not introduce a moving average process in the disturbance, i.e., orthogonality among errors is preserved. Another practical difference is that the FOD transformation preserves the sample size in panels with gaps, where FD would reduce the number of observations (Roodman, 2009a). ${ }^{12}$

The estimation results for equation (10) under the FOD transformation method are reported in Table 3, columns 3 to 6 . For each estimation using GMM (columns 3 to 6), we report the instrument count and the p-value of the Hansen test for the joint validity of all instruments (Hansen p-value full). ${ }^{13}$ For the system-GMM estimators (columns 4 and 6), we also report the p-value of the Hansen test for the validity of instruments used in the transformed model (Hansen p-value transformed model), ignoring the instruments for the levels, and the p-value of the Hansen test for the additional instruments used in the equation in levels (Difference-in-Hansen p-value). The latter tells us about the mean stationarity condition needed for the validity of the level instruments. Finally, we report the Arellano-Bond test for third-order serial correlations in the residuals. ${ }^{14}$ We also estimated equation (10) using OLS and fixed

\footnotetext{
12 Note that precisely the same instrument set would be used to estimate the model in orthogonal deviations.

13 For a comparison of estimates of comparable models under the restricted version of the RA model, see Appendix B.

14 As reported by Roodman (2009a), in general, we check for serial correlation of order $l$ in levels by looking for correlation of order $l+1$ in differences. Because current consumption depends on both past and future consumption in our model, this is an autoregressive process of order 2
} 
effects (FE) (columns 1 and 2 in Table 3) and no additional covariates. As Bond (2002) points out, while in the OLS regression the lagged dependent variable is positively correlated with the error, biasing its coefficient estimate upward, the opposite is the case in the FE model. Good estimates of the true parameters should therefore lie in the range determined by these values. The models in columns 3 and 4 of Table 3 use the DIFF-GMM estimator and the system-GMM estimator, respectively, on the specification with no additional covariates. In column 3, we consider prices as predetermined and instrument them in GMM style, and we do not use any strategy to reduce the instruments count. Models in columns 5 and 6 use DIFF-GMM and system-GMM estimators on the full specification, prices are considered as predetermined and instrumented in GMM style, and we reduce the number of instruments by truncating the lag length.

The estimates reported for our preferred specification, system-GMM with FOD and covariates (column 6 in Table 3), are consistent with the rational addiction framework. First, past consumption has a significant positive coefficient. Second, future consumption also has a significant positive coefficient, supporting the idea that smokers' behavior is forward-looking. Third, the coefficient of lagged price is greater than the coefficient of lead price, giving rise to a positive discount rate. Fourth, we obtain a negative coefficient on the current price and a positive coefficient on both past and future prices. Therefore, the signs on the two consumption variables and the three price variables conform to theoretical predictions. Our preferred specification also satisfies the necessary condition for a stable equilibrium, i.e., that the sum of the coefficients on past and future consumption is less than unity, and that the sum of the three price coefficients is less than zero. Among the sociodemographic variables included, gender, the level of education, the number of hours worked per day, and monthly wages are all statistically significant and take on the expected sign. The p-values of the Hansen $J$ statistic for overidentifying restrictions for the full model (Hansen p-value full), of the additional instruments used in system-GMM compared to DIFF-GMM, i.e., the instruments for the level equation (Hansen p-value transformed model), and of the Difference-in-Hansen test are all consistent with the null hypothesis of no overidentification. Finally, the Arellano-Bond test for autocorrelation in the residuals does not detect third-order serial correlation.

Comparing our estimates with those of the previous three papers which estimated the general version of the rational addiction demand equation is not easy, because of differences in specification, data, and estimation methods. Becker et al. (1990) used aggregate panel data and FESLS which is well known to produce inconsistent estimates of the parameters of interest in presence of endogeneity (Baltagi and Griffin, 2001). However the sign and magnitude of their estimated past and future consumption coefficients in Table 6 column 7 (0.505 and 0.350 respectively) are comparable to those in our preferred specification ( 0.407 and 0.399 , respectively, in Table 3 column 6). In addition, as in our preferred specification, the sum of these two coefficients in Table 3 column 6 is less than unity, as required for a stable equilibrium. Chaloupka (1991) uses micro data on individual consumption of cigarettes in three adjacent time periods and FE2SLS to estimate the general RA demand equation. Results comparable to our estimates in Table 3 column 6 are presented in his Table 1 column 2 for the full sample. The sign and magnitude of his estimated past and future consumption coefficients ( 0.516 and 0.268 , respectively) are comparable to ours, but the future consumption coefficient is not statistically significant. Past and future price coefficients are also not statistically significantly different from zero. Finally, Waters and Sloan (1995) use individual data on alcohol consumption in the US for three years. The first column of their Table 2 shows positive and significant coefficients on past and future consumption. Current, past and future prices are also significant and have the predicted signs, but their sum is larger than zero which suggests unstable consumption. In addition, Waters and Sloan (1995) impose the constraint of a discount rate equal to 0.05 .

\subsection{Time-consistency test}

We implemented the tests of time-consistency on the estimated parameters from our preferred specification (model 6 in Table 3). As explained in Section 5 our test boils down to testing the null hypothesis $\hat{\phi}_{F} \hat{\varphi}_{L}=\hat{\phi}_{L} \hat{\varphi}_{F}$. The test statistic has a $\chi^{2}$ distribution with 1 degree of freedom under the null hypothesis. We obtain $\chi^{2}(1)=0.00$ with a Prob $>\chi^{2}=0.991$. Thus, we do not reject the null hypothesis of time-consistency at the $5 \%$ level. Consistent with this result, the estimated upper bound for the present bias parameter $\beta$ is $\beta_{\max }=\frac{\hat{\phi}_{F} \hat{\varphi}_{L}}{\hat{\phi}_{L} \hat{\varphi}_{F}}=0.991$.

The estimated discount factor $\delta=\hat{\varphi}_{F} / \hat{\varphi}_{L}=0.988$ corresponds to a long-run discount rate of $1.2 \%$. Compared to the previous literature that estimated the general specification of the rational addiction model, our set of results suggests a pretty standard time preference structure, with no evidence of time-inconsistency and with a reasonably small discount rate. In fact, besides Waters and Sloan (1995), who exogenously imposed a discount factor of 0.95, Chaloupka (1991) estimated a long-run discount factor of around 0.52 (ratio of future-to-past consumption coefficients in Table 1 column 2) corresponding to a discount rate of $93 \%$. On the other hand, Becker et al. (1990) obtained an estimated long-run discount factor of 1.01 (ratio of ratio of future-to-past consumption coefficients in Table 6 column 7) corresponding to a negative discount rate of around $-1 \%$.

\subsection{Dynamics of consumption}

Our demand equation is a second-order difference equation in current consumption. The roots of this difference equation are useful for describing the dynamics of consumption and are positive if and only if consumption is addictive (Chaloupka, 1990). For equation (10), these roots are $\lambda_{1,2}=\frac{1 \pm \sqrt{1-4 \phi_{L} \phi_{F}}}{2 \phi_{L}}$ with $4 \phi_{L} \phi_{F}<1$ from the assumption of concavity. BGM notes that both roots are real

(AR2), and we have second-order serial correlation by construction. Therefore, for the validity of our instrument set, we need to detect no serial correlation of order 3 in the residuals. 
and depend on the sign of $\phi_{L}$ and $\phi_{F}$. Both roots are positive if and only if consumption is addictive ( $\left.\phi_{L}>0\right)$; both roots will be zero or negative otherwise. The smaller root, $\lambda_{1}$, known as the stable root, gives the change in current consumption resulting from a shock to future consumption. The inverse of the larger root $\lambda_{2}$ indicates the impact of a shock to past consumption on current consumption. These shocks may be the result of a change in any of the factors affecting the demand for cigarettes. In our preferred specification (system GMM with FOD) $\phi_{L}=0.399$ and both roots are positive (unstable root $\lambda_{2}=1.957$; stable root $\lambda_{1}=0.500$ ), confirming that cigarette consumption is actually addictive. ${ }^{15}$

Laporte et al. (2017) investigate whether the strength of the unstable root, $\lambda_{2}$, which theory predicts will be present in the individuals optimal solution trajectory, relative to the stable root, $\lambda_{1}$, makes it difficult to obtain reliable estimates of the parameters of the rational addiction demand equation even when the true Data Generating Process (DGP) possesses the key characteristics of the RA model. This might explain, according to Laporte et al. (2017), why the estimates of the long-run discount factor vary so widely in the RA empirical literature. However, we obtain sensible and statistically significant values of the estimated parameters of the model, including the long-run discount factor, as explained above. In addition, the estimated coefficients of lagged and lead consumption in our preferred specification (column 6 in Table 3) satisfy both the Becker-Murphy stability condition that the sum of the coefficients on past and future consumption is less than unity (0.805) (Becker et al., 1990), and the condition for the model to exhibit saddle-point dynamics $\left(\phi_{F} \phi_{L}<0.25\right.$, which in our case is 0.162$)$.

\section{Conclusions}

This paper addresses one of the main theoretical and empirical shortcomings of the rational addiction model, namely, that forwardlooking behavior, implied by theory, does not necessarily imply time-consistency. Even when forward-looking behavior is supported by data, the dynamic consumption equation derived from rational addiction theory does not provide evidence in favor of timeconsistent preferences against a model with dynamic inconsistency (Gruber and Köszegi, 2001).

We show that the possibility of testing for time-consistency is nested within the rational addiction demand equation. Rather than relying on additional assumptions or on a different theoretical or empirical framework, we use price effects and the rarely estimated general formulation of the rational addiction demand equation to implement a test of time-consistency. The test's purpose is to check whether the consumers behind our data reveal time-consistent or naïve time-inconsistent preferences. Our estimates of the general rational addiction demand equation conform to theory, and our test of time-consistency does not reject the hypothesis that consumers exponentially discount future utilities.

The value added of our contribution is to show that the information extracted from a general rational addiction demand equation is sufficient to test for both forward-looking behavior and time-consistency of the underlying consumers.

This has relevant policy implications for the optimal taxation of addictive goods. As Gruber and Köszegi (2002, 2004) point out, when agents are time-inconsistent positive taxation is optimal even in the absence of externalities, as time-inconsistency will imply self-control problems and the optimal future consumption path planned at time $t$ will not be realized by the agent. Hence, in the case of time-inconsistent agents, taxes on addictive goods are substantially larger than those for time-consistent consumers. O'Donoghue and Rabin (2006), considering nonaddictive unhealthy goods with quasi-hyperbolic time preferences, shows that the optimal tax is proportional to $(1-\beta)$ times the marginal health cost of consumption and that even very small levels of present bias ( $\beta$ close to 1 ) produce significantly large optimal taxes.

In this context, having the possibility of testing for time-consistency can be of great value to the policy-makers. In addition, the possibility of estimating at least an upper bound for the present bias parameter $\left(\beta_{\max }\right)$ would enable the policy-makers to compute the lower bound of an optimal tax on addictive goods by extending the O'Donoghue and Rabin (2006) optimal taxation model to addictive consumption, which would be an interesting avenue for future research.

\section{Appendix A. Mathematical appendix}

Extending the Rational addiction model to quasi-hyperbolic discounting, the consumer's problem becomes the following:

$$
\begin{array}{r}
\operatorname{Max} U_{t}\left(Y_{t}, C_{t}, A_{t}, e_{t}\right)+\beta \sum_{i=1}^{\infty} \delta^{i} U_{t+i}\left(Y_{t+i}, C_{t+i}, A_{t+i}, e_{t+i}\right) \\
\text { s.t. }\left(Y_{t}+P_{t} C_{t}\right)+\sum_{i=1}^{\infty} \delta^{i}\left(Y_{t+i}+P_{t+i} C_{t+i}\right)=W_{0}
\end{array}
$$

Taking a quadratic function in the three arguments, the resulting instantaneous utility is as follows:

$$
U_{t}=b_{Y} Y_{t}+b_{C} C_{t}+b_{A} A_{t}+\frac{1}{2} U_{Y Y} Y_{t}^{2}+\frac{1}{2} U_{C C} C_{t}^{2}+\frac{1}{2} U_{A A} A_{t}^{2}+U_{Y A} Y_{t} A_{t}+U_{C A} C_{t} A_{t}+U_{Y C} Y_{t} C_{t}
$$

\footnotetext{
${ }^{15}$ Notice that this is exactly what we expect for the rational addiction model to be the solution of an individual's intertemporal optimization problem: we should find one stable and one unstable root. Since we are using the difference equation for our empirical work, this corresponds to having one root less than one and one root greater than one. See Laporte et al. (2017) p. 4.
} 
The maximized value of utility becomes the following:

$$
\begin{aligned}
V^{*}(\cdot)=\max _{C_{t}, Y_{t}}\left\{U_{t}\left(Y_{t}, C_{t}, A_{t}\right)+\beta \sum_{i=1}^{\infty} \delta^{i} U_{t+i}\left(Y_{t+i}, C_{t+i}, A_{t+i}\right)-\right. \\
\left.\lambda\left[\left(Y_{t}+P_{t} C_{t}\right)+\sum_{i=1}^{\infty} \delta^{i}\left(Y_{t+i}+P_{t+i} C_{t+i}\right)-W_{0}\right]\right\}
\end{aligned}
$$

which can be rewritten as follows:

$$
\begin{gathered}
V^{*}(\cdot)=\lambda W_{0}+\max _{C_{t}, Y_{t}}\left\{U_{t}\left(Y_{t}, C_{t}, A_{t}\right)+\beta \sum_{i=1}^{\infty} \delta^{i} U_{t+i}\left(Y_{t+i}, C_{t+i}, A_{t+i}\right)-\right. \\
\left.\lambda\left[\left(Y_{t}+P_{t} C_{t}\right)+\sum_{i=1}^{\infty} \delta^{i}\left(Y_{t+i}+P_{t+i} C_{t+i}\right)\right]\right\}
\end{gathered}
$$

where $\lambda$ is the marginal utility of wealth. Maximizing (14) with respect to $Y_{t}$ and subject to the budget constraint results in the following first-order condition for $Y_{t}$ :

$$
Y_{t}=\frac{1}{U_{Y Y}}\left[\lambda-U_{Y A} A_{t}-U_{Y C} C_{t}-b_{Y}\right]
$$

Plugging this result into (17) results in the maximization problem being a function of only the consumption of the addictive good and the stock of the addictive good:

$$
\begin{aligned}
& V^{*}(\cdot)=\lambda W_{0}+\max _{C_{t}}\left\{U_{t}\left(C_{t}, A_{t}\right)+\beta \sum_{i=1}^{\infty} \delta^{i} U_{t+i}\left(C_{t+i}, A_{t+i}\right)-\right. \\
& \left.\lambda\left[B_{t}\left(C_{t}, P_{t}, A_{t}\right)+\sum_{i=1}^{\infty} \delta^{i} B_{t+i}\left(C_{t}, P_{t}, A_{t}\right)\right]\right\}
\end{aligned}
$$

where

$$
\begin{aligned}
& U_{t}\left(C_{t}, A_{t}\right)=\alpha_{k}+\alpha_{A} A_{t}+\alpha_{C} C_{t}+\frac{1}{2} \alpha_{A A} A_{t}^{2}+\frac{1}{2} \alpha_{C C} C_{t}^{2}+\alpha_{C A} A_{t} C_{t} \\
& B_{t}\left(C_{t}, P_{t}, A_{t}\right)=\tau_{k}+\tau_{A} A_{t}+\left(P_{t}-\tau_{C}\right) C_{t}
\end{aligned}
$$

and

$$
\begin{aligned}
\alpha_{k} & =-\frac{\left(\lambda-b_{Y}\right)^{2}}{2 U_{Y Y}} \\
\alpha_{A} & =b_{A}-b_{Y} \frac{U_{Y A}}{U_{Y Y}} \\
\alpha_{C} & =b_{C}-b_{Y} \frac{U_{Y C}}{U_{Y Y}} \\
\tau_{k} & =\frac{\lambda-b_{y}}{U_{Y Y}} \\
\tau_{C} & =\frac{U_{Y C}}{U_{Y Y}}
\end{aligned}
$$

$$
\begin{aligned}
\alpha_{A A} & =U_{A A}-\frac{\left(U_{Y A}\right)^{2}}{U_{Y Y}} \\
\alpha_{C C} & =U_{C C}-\frac{\left(U_{Y C}\right)^{2}}{U_{Y Y}} \\
\alpha_{C A} & =U_{C A}-\frac{U_{Y C} U_{Y A}}{U_{Y Y}} \\
\tau_{A} & =-\frac{U_{Y A}}{U_{Y Y}}
\end{aligned}
$$

Considering $A_{t}=(1-\gamma) A_{t-1}+C_{t-1}$ and maximizing (19) with respect to $C_{t}$ implies the following first-order condition:

$$
\begin{aligned}
\frac{\partial V(\cdot)}{\partial C_{t}}= & \frac{\partial U_{t}(\cdot)}{\partial C_{t}}+\beta \delta \frac{\partial U_{t+1}(\cdot)}{\partial A_{t+1}} \frac{\partial A_{t+1}}{\partial C_{t}}+\beta \delta^{2} \frac{\partial U_{t+2}(\cdot)}{\partial A_{t+2}} \frac{\partial A_{t+2}}{\partial A_{t+1}} \frac{\partial A_{t+1}}{\partial C_{t}}+\ldots \\
& -\lambda\left[\frac{\partial B_{t}(\cdot)}{\partial C_{t}}+\delta \frac{\partial B_{t+1}(\cdot)}{\partial A_{t+1}} \frac{\partial A_{t+1}}{\partial C_{t}}+\delta^{2} \frac{\partial B_{t+2}(\cdot)}{\partial A_{t+2}} \frac{\partial A_{t+2}}{\partial A_{t+1}} \frac{\partial A_{t+1}}{\partial C_{t}}+\ldots\right]=0
\end{aligned}
$$


Noting that

$$
\begin{aligned}
\frac{\partial U\left(C_{t}, A_{t}\right)}{\partial C_{t}} & =\alpha_{C}+\alpha_{C C} C_{t}+\alpha_{C A} A_{t} \equiv U_{C, t} \\
\frac{\partial U\left(C_{t}, A_{t}\right)}{\partial A_{t}} & =\alpha_{A}+\alpha_{A A} A_{t}+\alpha_{C A} C_{t} \equiv U_{A, t} \\
\frac{\partial B_{t}\left(C_{t}, P_{t}, A_{t}\right)}{\partial C_{t}} & =P_{t}-\tau_{C} \\
\frac{\partial B_{t}\left(C_{t}, P_{t}, A_{t}\right)}{\partial A_{t}} & =\tau_{A} \\
\frac{\partial A_{t+i+1}}{\partial A_{t+1}} & =1-\gamma, \text { and } \\
\frac{\partial A_{t+1}}{\partial C_{t}} & =1
\end{aligned}
$$

and substituting these definitions into equation (22) the first order condition can be rewritten as follows:

$$
\begin{aligned}
\frac{\partial V(\cdot)}{\partial C_{t}}= & U_{C, t}+\beta \delta U_{A, t+1}+\beta \delta^{2}(1-\gamma) U_{A, t+2}+\beta \delta^{3}(1-\gamma)^{2} U_{A, t+3}+\ldots \\
& -\lambda\left[P_{t}-\tau_{C}+\delta \tau_{A}+\delta^{2}(1-\gamma) \tau_{A}+\delta^{3}(1-\gamma)^{2} \tau_{A}+\ldots\right] \\
= & U_{C, t}+\beta \sum_{i=1}^{\infty} \delta^{i}(1-\gamma)^{i-1} U_{A, t+1}-\lambda\left[P_{t}-\tau_{C}+\sum_{i=1}^{\infty} \delta^{i}(1-\gamma)^{i-1} \tau_{A}\right]=0
\end{aligned}
$$

which implies

$$
U_{C, t}=\lambda P_{t}-\lambda \tau_{C}-\beta \sum_{i=1}^{\infty} \delta^{i}(1-\gamma)^{i-1} U_{A, t+i}+\lambda \tau_{A} \sum_{i=1}^{\infty} \delta^{i}(1-\gamma)^{i-1}
$$

The consumption demand equation can be obtained starting from equation (23), as similar equations can be derived for each time period. Consider the differences $\delta(1-\gamma) U_{C, t}-U_{C, t-1}$ and $\delta(1-\gamma) U_{C, t+1}-U_{C, t}$. Using equation (23), they can be written as

$$
\begin{aligned}
& \delta(1-\gamma) U_{C, t}-U_{C, t-1}=\lambda \delta(1-\gamma) P_{t}-\lambda P_{t-1}+\beta \delta V_{A, t}+\kappa \\
& \delta(1-\gamma) U_{C, t+1}-U_{C, t}=\lambda \delta(1-\gamma) P_{t+1}-\lambda P_{t}+\beta \delta V_{A, t+1}+\kappa
\end{aligned}
$$

with $\kappa=\lambda\left[\tau_{C}(1-\delta(1-\gamma))-\tau_{A} \delta\right]$. Now, multiply both sides of equation (24) by $(1-\gamma)$ and subtract it from equation (25):

$$
\begin{aligned}
& \delta(1-\gamma) U_{C, t+1}-U_{C, t}-\delta(1-\gamma)^{2} U_{C, t}+(1-\gamma) U_{C, t-1}= \\
& \gamma \kappa+\lambda \delta(1-\gamma) P_{t+1}-\lambda P_{t}+\beta \delta V_{A, t+1}-\left[\lambda \delta(1-\gamma)^{2} P_{t}-\lambda(1-\gamma) P_{t-1}+\beta \delta(1-\gamma) V_{A, t}\right] .
\end{aligned}
$$

Substituting $U_{C, i}$ and $V_{A, i}$ with their definitions, using $A_{t}=(1-\gamma) A_{t-1}+C_{t-1}$ to eliminate the stock of habits, and solving for $C_{t}$ produces the demand equation, we obtain the following:

$$
C_{t}=\theta_{0}+\theta_{L} C_{t-1}+\theta_{F} \delta C_{t+1}-\theta_{1}\left[1+(1-\gamma)^{2} \delta\right] P_{t}+\theta_{1}(1-\gamma) P_{t-1}+\theta_{1} \delta(1-\gamma) P_{t+1}
$$

where

$$
\begin{aligned}
\Omega & =\alpha_{C A}(1+\beta) \delta(1-\gamma)-\alpha_{A A} \beta \delta-\alpha_{C C}\left[1+\delta(1-\gamma)^{2}\right]>0 \\
\theta_{0} & =\frac{\gamma}{\Omega}\left[\kappa+\alpha_{C}(\delta(1-\gamma)-1)-\alpha_{A} \beta \delta\right] \\
\theta_{L} & =\frac{1}{\Omega}\left[\alpha_{C A}-\alpha_{C C}(1-\gamma)\right]>0 \\
\theta_{F} & =\frac{1}{\Omega}\left[\beta \alpha_{C A}-\alpha_{C C}(1-\gamma)\right]>0 \\
\theta_{1} & =\frac{\lambda}{\Omega}>0 .
\end{aligned}
$$

\section{Appendix B. Estimates of the restricted Rational Addiction model}

Table 4 shows estimates of the restricted or standard Rational Addition model presented in equation (2). We estimated the same six models presented in Table 3 and we used the same econometric strategy and the same set of control variables. As the general 
Table 4

Estimates of the Restricted Rational Addiction Models .

\begin{tabular}{|c|c|c|c|c|c|c|}
\hline Parameter & $\begin{array}{l}\text { OLS } \\
(1)\end{array}$ & $\begin{array}{l}\text { Fixed Effects } \\
\text { (2) }\end{array}$ & $\begin{array}{l}\text { DIFF-GMM } \\
\text { (3) }\end{array}$ & $\begin{array}{l}\text { SYS-GMM } \\
\text { (4) }\end{array}$ & $\begin{array}{l}\text { DIFF-GMM } \\
\text { (5) }\end{array}$ & $\begin{array}{l}\text { SYS-GMM } \\
\text { (6) }\end{array}$ \\
\hline$C_{t-1}$ & $\begin{array}{l}0.395^{* * *} \\
(0.009)\end{array}$ & $\begin{array}{l}-0.017 \\
(0.012)\end{array}$ & $\begin{array}{l}0.354 * * * \\
(0.034)\end{array}$ & $\begin{array}{l}0.378^{* * * *} \\
(0.032)\end{array}$ & $\begin{array}{l}0.379 * * * \\
(0.059)\end{array}$ & $\begin{array}{l}0.413^{* * *} \\
(0.045)\end{array}$ \\
\hline$C_{t+1}$ & $\begin{array}{l}0.413^{* * *} \\
(0.009)\end{array}$ & $\begin{array}{l}-0.015 \\
(0.012)\end{array}$ & $\begin{array}{l}0.276^{* * *} \\
(0.040)\end{array}$ & $\begin{array}{l}0.328^{\text {**** }} \\
(0.037)\end{array}$ & $\begin{array}{l}0.282^{\text {**** }} \\
(0.057)\end{array}$ & $\begin{array}{l}0.383^{* * * *} \\
(0.047)\end{array}$ \\
\hline$P_{t}$ & $\begin{array}{l}-0.009^{*} \\
(0.005)\end{array}$ & $\begin{array}{l}0.006 \\
(0.008)\end{array}$ & $\begin{array}{l}-0.009 \\
(0.009)\end{array}$ & $\begin{array}{l}-0.008 \\
(0.009)\end{array}$ & $\begin{array}{l}-0.010 \\
(0.044)\end{array}$ & $\begin{array}{l}-0.030^{* *} \\
(0.012)\end{array}$ \\
\hline Controls & & & & & yes & yes \\
\hline $\begin{array}{l}\text { Time dummies } \\
\text { Constant }\end{array}$ & $\begin{array}{l}\text { yes } \\
3.298^{* * *} \\
(0.176)\end{array}$ & $\begin{array}{l}\text { yes } \\
16.758^{* * * *} \\
(0.408)\end{array}$ & yes & yes & yes & yes \\
\hline Hansen p-val full & & & 0.205 & 0.109 & 0.174 & 0.251 \\
\hline Hansen p-val transf. model & & & & 0.250 & & 0.371 \\
\hline Diff-in-Hansen p-value & & & & 0.022 & & 0.259 \\
\hline p-val AR(2) Arellano-Bond in FD & & & 0.000 & 0.000 & 0.000 & 0.000 \\
\hline p-val AR(3) Arellano-Bond in FD & & & 0.918 & 0.680 & 0.563 & 0.887 \\
\hline \# Obs & 24,006 & 24,006 & 18,473 & 24,013 & 13,007 & 17,387 \\
\hline Instruments count & & & 676 & 741 & 200 & 292 \\
\hline
\end{tabular}

Notes: Robust SE in parentheses. Windmeijer correction used in models (3)-(6).

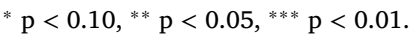

formulation of the RA model, presented in equation (3), encompasses the restricted version, it is possible to compare estimates of the common coefficients in the two models, i.e., past and future consumption and current price coefficients. Comparing the first three rows of Table 3 with those in Table 4 , it is possible to note how the coefficients of the consumption variables, $C_{t-1}$ and $C_{t+1}$, show hardly any difference between the general and the restricted versions. Somewhat larger differences, but still very limited, are instead observed for the current price coefficients, $P_{t}$. The only statistically different coefficient (at $5 \%$ significance level) is observed for the current price coefficient in column (6), which is expected as it is the only specification in which lead and lagged price coefficients are significant. The sign of the coefficient, however, is consistent, and the significance level is improved in the general version of the RA model.

\section{Supplementary material}

Supplementary material associated with this article can be found, in the online version, at doi:10.1016/j.jhealeco.2021.102546.

\section{CRediT authorship contribution statement}

Luca Piccoli: Conceptualization, Methodology, Software, Formal analysis, Data curation, Writing - original draft. Silvia Tiezzi: Conceptualization, Methodology, Software, Formal analysis, Data curation, Writing - original draft.

\section{References}

Acland, D., Levy, M., 2015. Habit formation, naivet, and projection bias in gym attendance. Manage Sci 61 (1), 146-160.

Ainslie, G., 1992. Picoeconomics: The strategic interaction of successive motivational states within the person. Cambridge University Press, Cambridge, U.K, New York.

Angeletos, G., Laibson, D., Repetto, A., Tobacman, J., Weinberg, S., 2001. The hyperbolic consumption model: calibration, simulation and empirical evaluation. J Econ Perspect 15 (3), 47-68.

Arellano, M., Bond, S., 1991. Some tests of specification for panel data: monte carlo evidence and an application to employment equations. Rev Econ Stud 58, $277-297$. Arellano, M., Bover, O., 1995. Another look at the instrumental variable estimation of error-component models. J Econom 68, $29-51$.

Ariely, D., Wertenbroch, K., 2002. Procrastination, deadlines, and performance: self-control by precommitment. Psychol Sci 13(3), $219-224$.

Baltagi, B., Geishecker, I., 2006. Rational alcohol addiction: evidence from the russian longitudinal monitoring survey. Health Econ 15(9), 893-914.

Baltagi, B., Griffin, G.M., 2001. The econometrics of rational addiction: the case of cigarettes. J Bus Econ Stat 11(4), 449-454.

Baltagi, B., Griffin, G.M., 2002. The econometrics of rational addiction: the case of cigarettes. Health Econ 11, $485-491$.

Barro, R., 1999. Ramsey meets laibson in the neoclassical growth model. Q J Econ 114, 1125-1152.

Becker, G., Grossman, M., Murphy, K., 1990. An empirical analysis of cigarette addiction. NBER Work Pap 3322.

Becker, G., Grossman, M., Murphy, K., 1994. An empirical analysis of cigarette addiction. Am Econ Rev 396-418.

Becker, G., Murphy, K., 1988. A theory of rational addiction. J Political Econ 96, 675-701.

Biørn, E., Klette, T., 1998. Panel data with errors-in-variables: essential and redundant orthogonality conditions in gmm-estimation. Econ Lett 59(3), 275-282.

Blundell, R., Bond, S., 1998. Initial conditions and moment restrictions in dynamic panel data models. J Econom 87, 115-143.

Bond, S.R., 2002. Dynamic panel data models: a guide to micro data methods and practice. Portuguese Econ J 1 (2), $141-162$.

Boyer, M., 1978. A habit forming optimal growth model. Int Econ Rev (Philadelphia) 19, 585-609.

Boyer, M., 1983. Rational demand and expenditures patterns under habit formation. J Econ Theory 31, 27-53.

Bun, M., Kleibergen, F., 2013. Identification and inference in moments based analysis of linear dynamic panel data models. UvA-Econometrics Discussion Paper University of Amsterdam 07.

Bun, M., Sarafidis, V., 2013. Dynamic panel data models. UvA-Econometrics Discussion Paper - University of Amsterdam 01.

Chaloupka, F., 1990. Rational addictive behaviour and cigarette smoking. NBER Work Pap 3268. 
Chaloupka, F., 1991. Rational addictive behavior and cigarette smoking. J Political Econ 99 (4), 722-742.

Chaloupka, F., Levy, M., White, J., 2019. Estimating biases in smoking cessation: evidence from a field experiment. NBER Work Pap 26522.

Della Vigna, S., 2009. Psychology and economics: evidence from the field. J Econ Lit 47 (2), 315-372.

Della Vigna, S., Malmendier, U., 2006. Paying not to go to the gym. Am Econ Rev 96 (3), 694-719.

Della Vigna, S., Paserman, D., 2005. Job search and impatience. J Labour Econ 23 (3), 527-588.

Diamond, P., Köszegi, B., 2003. Quasi-hyperbolic discounting and retirement. J Public Econ 87 (9-10), 1839-1872.

Fang, H., Silverman, D., 2009. Time-inconsistency and welfare program participation. evidence from the nlsy. Int Econ Rev (Philadelphia) 50 (4), 1043-1076.

Gerry, C.J., Papadopoulos, G., 2015. Sample attrition in the rlms, 2001-10: lessons for longitudinal analysis and an application in health. Econ Transition 23 (2), 425-468.

Grossman, M., Chaloupka, F., 1998. The demand for cocaine by young adults: a rational addiction approach. J Health Econ 17, $427-474$.

Grossman, M., Chaloupka, F., Sirtalan, I., 1998. An empirical analysis of alcohol addiction: results from monitoring the future panels. Econ Inq 36, 39-48.

Gruber, J., Köszegi, B., 2000. Is addiction rational? NBER Work Pap 7507.

Gruber, J., Köszegi, B., 2001. Is addiction rational? theory and evidence. Q J Econ CXVI (7244), 1261-1303.

Gruber, J., Köszegi, B., 2002. A theory of government regulation of addictive bads: optimal tax levels and tax incidence for cigarette excise taxation. NBER Work Pap 8777.

Gruber, J., Köszegi, B., 2004. Tax incidence when individuals are time-inconsistent: the case of cigarette excise taxes. J Public Econ 88 (9-10), $1959-1987$.

Halevy, Y., 2015. Time consistency: stationarity and time invariance. Econometrica 3 (1), 335-352.

Jones, A., Labeaga, J., 2003. Individual heterogeneity and censoring in panel data estimates of tobacco expenditure. J Appl Econ 18 (-), $157-177$.

Labeaga, J., 1993. Individual behaviour and tobacco consumption: a panel data approach. Health Econ 2, 103-112.

Labeaga, J., 1999. A double-hurdle rational addiction model with heterogeneity: estimating the demand for tobacco. J Econom 93 (1), 49-72.

Laibson, D., 1997. Golden eggs and hyperbolic discounting. Q J Econ 62 (2), 443-478.

Laibson, D., Repetto, A., Tobacman, J., 2007. Estimating Discount Functions with Consumption Choices Over the Lifecycle. NBER Working paper. NBER

Laporte, A., Rohit-Dass, A., Ferguson, B., 2017. Is the rational addiction model inherently impossible to estimate? J Health Econ 54 (2), 161-175.

Levy, M., 2010. An Empirical Analysis of Biases in Cigarette Addiction.

Liu, J., Liu, J., Hammit, J., Chou, S., 1999. The price elasticity of opium in taiwan, 1914-1942. J Health Econ 18, 795-810.

Loewenstein, G., Elster, J., 1992. Choice over time. Russell Sage, New York.

O’Donoghue, T., Rabin, M., 2006. Optimal sin taxes. J Public Econ 90 (10-11), 1825-1849.

Olekalns, N., Bardsley, P., 1996. Rational addiction to caffeine: an analysis of coffee consumption. J Political Econ 104, 1100-1104.

O'Donoghue, T., Rabin, M., 1999a. Doing it now or later. Am Econ Rev 89 (1), 103-124.

O’Donoghue, T., Rabin, M., 1999b. Addiction and Self-control. In: Elster, J. (Ed.), Addiction: Entries and Exits. New York: Russell Sage.

O’Donoghue, T., Rabin, M., 2002. Addiction and present biased preferences. Working Paper Department of Economics, University of California at Berkeley E02-312.

Paserman, D., 2008. Job search and hyperbolic discounting: structural estimation and policy evaluation. Econ J 118 (531), $1418-1452$.

Pollak, R., 1968. Consistent planning. Rev Econ Stud 35(2), 201-208.

Roodman, D., 2009. How to do xtabond2: an introduction to difference and system gmm in stata. Stata J 9 (1), 86-136.

Roodman, D., 2009. A note on the theme of too many instruments. Oxford Bullettin Econ Stat 71 (1), 135-158.

Saffer, H., Chaloupka, F., 1999. The demand for illicit drugs. Econ Inq 37, 401-411.

Shapiro, J., 2005. Is there a daily discount rate? evidence from the food stamp nutrition cycle. J Public Econ 89 (2), $303-325$.

Strotz, R., 1956. Myopia and inconsistency in dynamic utility maximization. Rev Econ Stud 23 (3), 165-180.

Törnqvist, L., 1936. The bank of Finland's consumption price. index.

Waters, T., Sloan, F., 1995. Why do people drink? tests of the rational addiction model. Appl Econ 27 (8), 727-736.

Windmeijer, F., 2005. A finite sample correction for the variance of linear efficient two-step gmm estimators. J Econom 126, 25-51.

Ziliak, J., 1997. Why do people drink? tests of the rational addiction model. J Bus Econ Stat 15, 419-431. 